\title{
Autoridade e educação: o desafio em face do ocaso da tradição
}

\author{
JOSÉ SÉRGIO FONSECA DE CARVALHO \\ Universidade de São Paulo, São Paulo, SP, Brasil
}

\section{RESUMO}

A discussão sobre o lugar da autoridade na educação escolar tem mobilizado intelectuais, professores e responsáveis por políticas públicas da área. Em geral, os discursos alternam-se entre a denúncia e o lamento; entre a rejeição de relações escolares fundadas na autoridade e a busca de restauração de uma suposta autoridade perdida. Este artigo procura ressaltar que, apesar das divergências teóricas e programáticas entre essas duas tendências dos discursos educacionais, elas têm um aspecto comum: não distinguem a obediência produzida por uma relação de autoridade - sempre fundada na confiança - daquela que emerge da violência, da coerção ou do mero apego à legalidade. Assim, o debate acerca dos dilemas e impasses vinculados ao ocaso da autoridade nas relações educativas, com base na emergência do mundo moderno, exige a compreensão da especificidade desse tipo de relação e dos regimes de temporalidade que orientam os nexos que as sociedades estabelecem entre presente, passado e futuro.

\section{PALAVRAS-CHAVE}

filosofia da educação; autoridade; Hannah Arendt; ética e educação. 


\title{
AUTHORITY AND EDUCATION: THE CHALLENGE IN LIGHT OF TRADITION'S DECLINE
}

\author{
ABSTRACT \\ Discussions about the place of authority in the educational process \\ have mobilized intellectuals, teachers and policy makers. In general the \\ discourses have alternated between complaint and lament; between the \\ rejection of school relations founded on authority and the restoration \\ of a supposed lost authority. This paper seeks to emphasize that, despite \\ the theoretical and programmatic differences between these two trends \\ of educational discourses, both have a common feature: they do not \\ distinguish obedience produced by a relationship of authority - always \\ founded on trust - from those that emerge as a result of violence, coercion \\ or mere attachment to legality. Thus, the debate about the dilemmas and \\ predicaments linked to decline of authority in educational relationships \\ in the modern world requires an understanding of the specificity of this \\ type of relationship and the temporal regimes that govern the relationships \\ that societies establish between present, past and future. \\ KEYWORDS \\ philosophy of education; authority; Hannah Arendt; ethics and education.
}

\section{AUTORIDAD Y EDUCACIÓN: EL DESAFÍO ANTE LA DECLINACIÓN DE LA TRADICIÓN}

RESUMEN

La discusión sobre el lugar de la autoridad en el proceso educativo escolar ha movilizado intelectuales, profesores y responsables políticos. Los discursos se alternan entre la queja y el lamento, entre el rechazo de las relaciones fundadas en la autoridad y la búsqueda de la restauración de una supuesta autoridad perdida. Este artículo pretende aclarar que, a pesar de las diferencias teóricas y programáticas entre estas dos tendencias de los discursos, ambas tienen un aspecto común: no distinguen la obediencia producida por una relación de autoridad-siempre fundada en la confianzade otras forma de obediencia, como las que son producidas por la violencia, la coacción o la adhesión a normas legales. Por lo tanto, el debate sobre los dilemas y dificultades relacionadas con la disminución de la autoridad en las relaciones educativas del mundo moderno requiere la comprensión de la especificidad de este tipo de relación y de los regímenes temporales que rigen los nexos que las sociedades establecen entre presente, pasado y futuro.

PALABRAS CLAVE

filosofía de la educación; autoridad; Hannah Arendt; ética y educación. 
Uma vez que não mais podemos recorrer a experiências autênticas e incontestes, comuns a todos, o próprio termo [autoridade] tornou-se enevoado por controvérsia e confusão. Pouca coisa acerca de sua natureza parece autoevidente ou mesmo compreensivel a todos, exceto o fato de que [...] a maior parte das pessoas concordam que o desenvolvimento do mundo moderno em nosso século foi acompanhado por uma crise constante de autoridade, sempre crescente e cada vez mais profunda. [...] O sintoma mais significativo dessa crise, a indicar sua profundeza e seriedade, é ter ela se espalhado em áreas pré-politicas tais como a criação dos filhos e a educação, em que a autoridade no sentido mais lato sempre fora aceita como uma necessidade natural, obviamente exigida tanto por imperativos naturais, o desamparo da criança, como por necessidade politica, a continuidade de uma civilização estabelecida, que somente pode ser garantida se os que são recém-chegados por nascimento forem guiados através de um mundo preestabelecido no qual nasceram como estrangeiros.

Arendt, 2006, p. 127

\section{APRESENTAÇÃO ${ }^{1}$}

O tema do ocaso e da ruptura da tradição perpassa toda a obra de Arendt: é central para suas teses acerca do advento da sociedade de massas e do totalitarismo e encontra-se na base de suas reflexões acerca da filosofia moral. É também o fio condutor de suas análises sobre as crises da autoridade e da educação no mundo moderno, pois é com a perda da tradição que entra em declínio uma forma específica de autoridade: aquela na qual o passado é concebido como um modelo capaz de atribuir um significado inconteste à prática educativa e imprimir durabilidade e coesão a uma comunidade cultural. É, pois, a partir de seu esvanecimento que Arendt enuncia o que the parece ser o grande impasse da educação contemporânea:

O problema da educação no mundo moderno está no fato de ela não poder abrir mão, em decorrência de sua própria natureza, nem da autoridade, nem da tradição, embora se veja obrigada a trilhar seu caminho em um mundo que não é estruturado pela autoridade nem tampouco mantido coeso pela tradição. (Arendt, 2006, p. 191)

Em sua perspectiva, educar implica sempre e necessariamente agir sobre um sujeito que se constrói em continuidade - ou ao menos em relação, ainda que de oposição ou confronto - com um mundo de heranças simbólicas cuja duração o transcende, tanto no passado como no futuro. Implica ainda que esse processo transcorre sempre em um contexto de assimetria entre educador e educando, derivada inicialmente do simples fato de que o mundo no qual este será iniciado precede-o no tempo e transcende o escopo de sua existência individual. Mas trata-se de uma

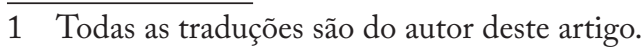


assimetria temporária, cuja legitimidade funda-se no reconhecimento de que o objetivo último do trabalho cotidiano do educador é a abolição, em um futuro predeterminado, da distância hierárquica que o separa daquele a quem ele educa. Assim, embora destinada a um progressivo desaparecimento ao longo da formação do sujeito, a relação de autoridade entre educador e educando jamais pode ser um elemento acessório ou um recurso eventual enquanto perdura esse processo. Não se pode, pois, escolher entre uma prática educativa com e sem autoridade; a autoridade é consubstancial à educação.

Daí o desafio insolúvel - ou a aporia - com o qual se depara o educador hoje. Seu trabalho exige respeito pelo passado e compromisso com o futuro, em um mundo que glorifica sem cessar o consumo e o gozo da vida presente. Ele estrutura-se a partir do reconhecimento da legitimidade de uma assimetria na relação entre educador e educando, em uma era que erigiu o princípio da igualdade como ideal programático das relações políticas e interpessoais:2 "Todas as pessoas nascem livres e iguais em dignidade e direitos", proclama o artigo primeiro da Declaração Universal dos Direitos Humanos. Seria essa postulada igualdade universal de direitos compatível com a autoridade do adulto sobre a criança, do professor sobre o aluno? $\mathrm{Ou}$, ao contrário, a aceitação da universalização de direitos implicaria um compromisso com a busca de superação de mais essa dissimetria, como no caso das desigualdades em relações de gênero ou em preconceitos étnico-raciais?

Ora, em que medida a preservação de um suposto espaço de assimetria legítima também não entraria em contradição com o movimento de emancipação crítica que marca o pensamento iluminista ${ }^{3}$ e todos os discursos pedagógicos que dele são tributários? A identificação imediata da autoridade com a aceitação de uma hierarquia - seja qual for sua fonte legitimadora - não implicaria ainda um desafio à lógica da democracia moderna, segundo a qual nenhum poder poderia legitimar-se sem a busca pela adesão daqueles sobre os quais se exerce? A noção moderna de um poder que se autoinstitui contratualmente, sem a necessidade de nenhum tipo de transcendência, é compatível com a preservação de um espaço no qual a dissimetria entre educadores e educandos é um pressuposto anterior à própria relação? Sua even-

2 A afirmação de que a igualdade de direitos e a liberdade individual seriam as "grandes criações axiológicas e normativas oriundas da razão moderna” (Renaut, 2004, p. 30) não implica, evidentemente, a crença de que a democracia moderna as tenha realizado plena ou satisfatoriamente; simplesmente explicita a adesão a um princípio pelo qual uma comunidade ou sociedade organiza a imagem de si e seus critérios de justiça e legitimidade, por exemplo.

3 Como salienta Gadamer (1999, p. 263), a oposição do Iluminismo a qualquer sorte de autoridade é uma marca de sua filosofia que considera "a autoridade como absoluto contrário da razão e da liberdade”. Ressalte-se, contudo, que essa oposição diz respeito às relações entre adultos que fazem uso de sua "razão pública". No campo da educação, entretanto, a autoridade em geral não se contrapõe à autonomia do sujeito, mas é, antes, seu pré-requisito. Para Kant (1993, p. 97), por exemplo, um professor deve "habituar seu aluno a tolerar uma coerção que pesa sobre sua liberdade, levando-o, simultaneamente, a fazer, por si mesmo, um bom uso de sua liberdade... [pois] o homem privado de educação não sabe se servir de sua vontade”. 
tual preservação não significaria a tentativa de deter um processo de democratização das relações sociais que, embora nunca logrado em sua plenitude, tem impulsionado transformações sociais significativas?

Em contrapartida, a recusa sumária da autoridade do educador e da legitimidade de um saber que se inscreve como herdeiro de certa tradição cultural não representaria a inviabilização da atividade educativa? A própria continuidade dos ideais modernos de emancipação crítica não dependeria - assim como sua renovação - da sujeição de jovens e crianças a um processo educacional que não escolheram e cuja aceitação do valor precede qualquer possível crítica a seu respeito? Ao recusar a autoridade como elemento inerente ao processo educacional não estaríamos, ingênua ou astutamente, propondo a substituição do ideal político de democratização da sociedade pela escola pelo ideal pedagógico de realizar uma democracia na escola? (Gauchet, 2002, p. 40).

A complexidade e o entrelaçamento das questões e perplexidades evocadas sugerem a pertinência - não obstante o desgaste da expressão - de se falar em uma crise da autoridade, com a condição de afastarmos de plano sua vinculação imediata, mas equívoca com as noções de degeneração ou decadência. Uma crise, lembra-nos Arendt (2006, p. 171), "dilacera fachadas e oblitera preconceitos" e, ao fazê-lo, simplesmente torna patente o fato de que "perdemos as respostas em que costumávamos nos apoiar sem nem sequer perceber que elas constituíam, originariamente, respostas a questões". A experiência da crise emerge, pois, da consciência do ocaso e da ruptura de uma tradição. Ela é fruto da constatação de que a herança que recebemos do passado - em forma de respostas teóricas ou práticas - já não tem autoridade sobre o presente. Em suas formas radicais, uma crise pode implicar algo ainda mais profundo: o esvanecimento dos próprios critérios por meio dos quais uma dada comunidade ou sociedade escolhe, valida e autoriza uma resposta. Mas a obsolescência de respostas e critérios herdados do passado não implica necessariamente a descartabilidade dos problemas que lhes deram origem. E por isso, mais que a decadência do instituído, a experiência da crise pode representar um convite à inovação instituinte. Assim concebida, uma crise pode ensejar a busca de novas respostas e o estabelecimento de critérios alternativos de validação intersubjetiva, pois

[...] as crises são precisamente esses momentos nos quais os homens se deparam com problemas que já não são mais capazes de solucionar, são momentos nos quais eles reassumem [reinvestissent] - e reinventam - as posições e os lugares que foram deixados vazios pelas respostas que já não funcionam. É porque o poder explicativo das velhas respostas se esgotou que algo de novo pode se iniciar. [...] Se nos propomos, pois, a repensar a "autoridade", é por considerar que a "crise" de todas as formas de autoridade com as quais somos hoje confrontados nos obriga a retomar "as posições e lugares deixados vazios", onde os esquemas tradicionais já não mais funcionam. (Revault D’Allones, 2006, p. 89)

E é na educação, mais que em qualquer outro âmbito de nossa existência comum, que somos impelidos a confrontar-nos com um vazio em relação às formas tradicionais de autoridade, não obstante o fato de que a crise não tenha inicialmente 
eclodido em seu domínio - mas no das relações políticas e da produção e circulação de conhecimentos. Contudo, sua intrusão nessa esfera específica - a da transmissibilidade intergeracional de experiências simbólicas que dão sentido de pertencimento a um mundo comum - atesta a profundidade das transformações em curso:

A perda geral de autoridade, de fato, não poderia encontrar expressão mais radical do que sua intrusão na esfera pré-política, na qual a autoridade parecia ser ditada pela própria natureza e independer de todas as mudanças históricas e condições políticas. $\mathrm{O}$ homem moderno, por outro lado, não poderia encontrar nenhuma expressão mais clara para sua insatisfação com o mundo, para seu desgosto com o estado de coisas, do que sua recusa em assumir, em face das crianças, a responsabilidade por tudo isso. É como se os pais dissessem todos os dias: - Nós mesmos não estamos muito seguros e à vontade neste mundo; como nos movimentarmos nele, o que saber, quais habilidades dominar, tudo isso também são mistérios para nós. Procurem tentar entender isso como puderem; de qualquer modo, vocês não têm o direito de exigir de nós satisfações. Somos inocentes, lavamos as nossas mãos. (Arendt, 2006, p. 188) ${ }^{4}$

É, pois, no plano das relações educativas que a recusa da assunção de um lugar de autoridade toma sua forma mais aguda, pois pode resultar no descaso pela transmissão de um legado de experiências simbólicas capazes de conferir durabilidade e sentido ao mundo que compartilhamos com os mais jovens que a ele chegam, mas também com aqueles que nos precederam e com os que nos sucederão na tarefa de sua renovação. Por isso, furtar-se a essa responsabilidade é simultaneamente abdicar do compromisso com a durabilidade desse mundo comum e abandonar à própria sorte as novas gerações que nele aportam, sem o amparo de uma tradição nem a familiaridade com um legado cultural que the confira inteligibilidade e sentido. Mas é também no domínio da educação - mais que em qualquer outro - que a noção de autoridade tem sido, pelo menos desde as primeiras décadas do século XX, objeto de disputas, denúncias e defesas apaixonadas e da produção de uma série de investigações empíricas e proposições normativas e legais.

\section{ENTRE RESTAURAÇÃO E ABOLIÇÃO: CONFUSÕES E PARADOXOS DOS DISCURSOS EDUCACIONAIS SOBRE A AUTORIDADE}

Mesmo uma rápida análise da diversidade de discursos acerca das relações entre educação e autoridade já pode revelar o caráter essencialmente polêmico das

4 O sentimento de culpa em virtude da desresponsabilização política de uma geração em relação a seus sucessores aparece de forma pungente em uma canção de Ivan Lins e Vitor Martins, sugestivamente intitulada "Aos nossos filhos": "Perdoem a cara amarrada/ Perdoem a falta de abraço/ Perdoem a falta de espaço/ Os dias eram assim./ Perdoem por tantos perigos/ Perdoem a falta de abrigo/ Perdoem a falta de amigos/ Os dias eram assim./ Perdoem a falta de folhas/ Perdoem a falta de ar/ Perdoem a falta de escolha/ Os dias eram assim". 
alegações e perspectivas que se colocam em constante conflito e, por vezes, em franca contradição. Ora evocam a falta de autoridade como causa de uma crescente deslegitimação da cultura escolar (que teria perdido a centralidade na formação das novas gerações), ora afirmam a força de sua presença nos processos de intensificação do governo de si e na normalização das condutas sociais. Ora a força da autoridade institucional é descrita como responsável pela violência simbólica por meio da qual a escola inculcaria um arbitrário cultural que legitimaria a reprodução das desigualdades, ora é à sua fragilidade que atribuem a maior parte dos problemas ligados à indisciplina, à incivilidade ou à violência por parte dos alunos. Em síntese, ou bem a relação educacional fundada na autoridade é descrita como um dispositivo coercitivo - herdado das hierarquias pré-modernas ou engendrado em função de novas exigências de conformação social -, ou bem se evoca a necessidade de sua restauraçẫo como remédio para os impasses de um processo educacional que perdeu a confiança em sua eficácia e a certeza de seu sentido.

Não obstante as claras divergências ideológicas que perpassam esses discursos, a multiplicidade de seus propósitos - descritivos, programáticos ou normativos - e a diversidade de perspectivas teóricas em que se apoiam, há entre eles ao menos um ponto comum: a tendência a fundir em um todo indistinto as noções de autoridade, força, violência e poder. Porque visam produzir a obediência como resultado e costumam aparecer interligados ou amalgamados em diferentes manifestações empíricas, esses fenômenos - de naturezas distintas - têm sido reiteradamente tratados como análogos ou equivalentes. A indistinção está presente tanto nos discursos ligados à denúncia e à rejeição da autoridade (equivocadamente equiparada à tirania, ao despotismo e a toda sorte de relações de dominação fundadas na coerção e na violência) como naqueles cuja pretensão seria a de sua restauração (por meios igualmente coercitivos).

Tomemos como exemplo dessa indistinção, em sua versão reacionária e restaurativa, o projeto de lei n. 267/2011, que tramita no Congresso Nacional por iniciativa de uma deputada paranaense. Visando coibir a indisciplina e a violência em sala de aula, o projeto de lei propõe a inclusão de um artigo (53-A) ao Estatuto da Criança e do Adolescente segundo o qual ficaria estabelecido que o "respeito à autoridade intelectual e moral [dos] docentes deve ser reconhecido legalmente como um dever da criança ou do adolescente" (grifo nosso). O descumprimento da medida legal, prevê seu parágrafo único, "sujeitará a criança ou o adolescente a suspensão por prazo determinado pela instituição de ensino e, na hipótese de reincidência grave, ao seu encaminhamento à autoridade judiciária competente". ${ }^{5}$ Assim, a autoridade é concebida não como fruto da confiança depositada no outro - naquele cuja posição assimétrica é tida por legítima porque reconhecida pelos que, de alguma forma, a ela se submetem -, mas como produto de uma ameaça de coerção. Ora, como nos lembra

5 Apresentado pela deputada Cida Borghetti (PP-PR) em fevereiro de 2011, o projeto de lei foi aprovado por unanimidade na Comissão de Seguridade Social e Família e tem recebido o apoio entusiasmado de uma parcela significativa de professores do ensino básico (Brasil, 2011). Seu teor e seu andamento estão disponíveis em: <http://www.camara.gov. br/proposicoesWeb/ fichadetramitacao?idProposicao=491406>. Acesso em: 18 jul. 2012. 
Arendt (2006, p. 920), a presença da autoridade no quadro de uma relação - seja ela política ou educacional - "exclui de imediato o uso de meios externos de coerção, [pois] quando se recorre à força é porque a autoridade, em si, falhou".

É muito pouco provável, embora, em tese, possível, que a juridicização das relações escolares resulte em obediência às normas por temor de uma sanção anunciada. Mas, ainda que o venha a fazer, ela jamais se estabelecerá como produto de uma relação de autoridade. Ao contrário da força - que pode ser posse de um indivíduo isolado ou permanecer em potência guardada em seu corpo ou num arsenal de armas -, a autoridade só emerge como fruto de uma relação: ela se dá nesse espaço entre-os-homens e é sempre mediada por instituições. E ela só se institui pelo reconhecimento de sua legitimidade, pois:

Se a autoridade existe, é em função da convocação ou da invocação dessa dimensão, ao mesmo tempo evanescente e onipresente, ligada ao papel capital do assentimento na vida social, que é o reconhecimento do legítimo no interior, para além de ou mesmo contra o legal. (Gauchet, 2002, p. 150, grifos nossos)

Sem essa dimensão do assentimento, que confere legitimidade à assimetria de lugares institucionais, a força da lei pode ensejar um mecanismo de dominação visando à produção da obediência, mas jamais será capaz de instituir uma relação de autoridade. Não se pode, pois - ao contrário do que diz a expressão corrente -, impor a autoridade; é ela que se interpóe em uma relação em que aquele que obedece o faz livremente. Tal como quando seguimos os conselhos de um médico - ou ouvimos as ponderações de um sacerdote - a quem creditamos autoridade em razão de seus conhecimentos, de sua sabedoria, enfim, de algo cuja compreensão pode mesmo nos escapar, mas a quem conferimos um lugar de autoridade porque acreditamo-lo capaz de um diagnóstico correto, de um ajuizamento justo, de um conselho apropriado. Assim, a autoridade manifesta o estabelecimento de uma relação de confiança, fundada na credibilidade e na crença: "sem essa dupla referência à credibilidade do lado de quem comanda e à crença do lado de quem obedece, seríamos incapazes de distinguir a autoridade da violência ou mesmo da persuasão"(Ricoeur, 2001,p. 109).

O objeto dessa credibilidade é sempre um alguém - no caráter singular de sua personalidade - a quem confiamos a capacidade de nos guiar naquilo cuja compreensão nos escapa, de nos orientar naquilo que (ainda?) não dominamos, de nos aconselhar diante de dilemas para os quais não vislumbramos saída. Mas - e esse é mais um paradoxo da noção de autoridade - esse alguém a quem se confere autoridade sempre age em nome de algo que o transcende: a fundação de uma comunidade política ou religiosa, a herança de um saber, a crença em um desígnio futuro, o enraizamento histórico de uma instituição; em síntese, age em nome de crenças, princípios e práticas que se inscrevem em um tempo e em um espaço comuns a uma coletividade. Por isso se espera daquele a quem se credita autoridade o respeito exemplar às regras e aos princípios em nome dos quais ele age e fala. A autoridade é, pois, simultaneamente representativa e pessoal; fundamenta-se em algum tipo de transcendência, mas sempre necessita da presença imanente daquele que a encarna. Ela fala em nome de uma comunidade, mas sempre pela voz singular de um indivíduo. 
Daí seu caráter fundamental no processo de formação educacional. O mundo a que chegam os novos - as crianças e os jovens a quem se educa - não é imediatamente inteligível. Ele é opaco, estruturado em práticas e valores que não são enunciados (e muitas vezes nem sequer são enunciáveis), dotado de linguagens cujas gramáticas nem sempre estão codificadas ou acessíveis. Em meio a um complexo conjunto de heranças materiais e simbólicas já estabelecidas, aqueles que são novos precisam ser acolhidos por alguém em que depositem confiança, a quem creditem a tarefa de guiá-los por entre demandas às quais ainda não se sentem capazes de responder por si sós, por entre problemas cuja solução exige discernimento, e não a aplicação mecânica de regras. Creditar autoridade a alguém significa, pois, reconhecê-lo capaz de esclarecer o obscuro, fazer escolhas e apontar rumos quando - ou enquanto - não somos capazes de fazê-lo exclusivamente com base em nossa própria capacidade de julgar.

Assim, reconhecer alguém como autoridade implica tê-lo como um exemplo ou referência por acreditar que ele saiba mais, possa mais ou tenha mais experiência no trato com este mundo, com suas linguagens e práticas. Não se trata de uma submissão cega a outrem, mas antes de uma filiação que não nos obriga, embora nos submeta a uma influência em princípio desigual. Uma submissão que, paradoxalmente, finca as bases a partir das quais alguém poderá vir a constituir-se como um sujeito autônomo. Isso porque quem quer que pense, julgue e analise por si mesmo, não o faz ex-nibilo. Ao contrário, sempre o faz baseado em referências, parâmetros ou modelos de excelência; enfim, de autoridades internalizadas que operam como recursos reflexivos ideais a orientarem escolhas, julgamentos e decisões.

Talvez seja a não aceitação desse paradoxo - a submissão prévia à autoridade como condição da possibilidade de constituição de um sujeito autônomo - que tem levado os discursos educacionais vinculados às pedagogias da autonomia (ou às chamadas pedagogias não diretivas) a um interminável combate programático em favor da abolição de qualquer referência a um lugar de autoridade na relação entre professores e alunos. Combate que inclui até mesmo a tentativa de abolição desses termos, identificados como signos de uma ordem tradicional e hierárquica. Nesses discursos, fala-se em crianças e jovens, mas não em alunos; em facilitadores da aprendizagem ou parceiros mais experientes, mas não em professores. Fala-se em aprendizagem ou construção de conhecimento, mas não em ensino ou transmissão de um legado de experiências simbólicas. O efeito dessa ênfase discursiva na ação e no pensamento do sujeito que aprende tem sido o declínio da função mediadora do ensino e da transmissão como elemento de ligação social e temporal.

Segundo essa modalidade de discurso pedagógico - e as psicologias do desenvolvimento em que se fundamentam -, tudo se passa como se bastasse o contato imediato da criança com as práticas sociais e suas linguagens para que estas venham a revelar-se na complexidade de seus usos, de seus sentidos e de seus mecanismos de validação intersubjetiva. Daí o caráter supostamente desnecessário - obsoleto mesmo - da referência a alguém a quem confiar a responsabilidade por sua iniciação na herança simbólica de que se constitui o mundo humano. Daí também a crença na incompatibilidade entre ensino, autoridade e autonomia do sujeito.

É a adesão a essa perspectiva que leva Jean Houssaye (2007,p. 181) a afirmar que, "longe de ser indispensável, a autoridade é o signo do fracasso da educação 
escolar. [...] [pois] não há problema de autoridade na escola. É a autoridade em si que cria os problemas". Na visão do autor, como na maior parte dos discursos pedagógicos contemporâneos, ${ }^{6}$ o exercício da autoridade é identificado com práticas marcadas pela "violência" e pela "coerção" e, ainda, com o exemplo de "recusa ao diálogo" (idem, p. 15-23) - portanto incompatível com uma formação voltada para a autonomia e liberdade dos educandos. Uma escola liberada da autoridade deveria dedicar-se a construir "relações simétricas" e desenvolver "processos de socialização" e novas formas de "relação com o saber" (idem, p. 181). Assim, ela dispensaria a mediação do professor e da instituição como fontes legítimas de orientação e justificação de escolhas, regras ou princípios. Em síntese, a emergência e a centralidade da noção de aprendizagem como construção pessoal do saber pretendem tornar obsoleta a noção de transmissão por meio do ensino.

Ora, por mais que reconheçamos a pertinência das críticas às formas coercitivas e violentas de socialização escolar e à inadequação de práticas pedagógicas que venham a ferir a dignidade dos alunos, o fato é que o desprezo pelo papel de um mediador autorizado que se interponha entre o saber e o sujeito que aprende - seja o professor ou a própria instituição - tende a ignorar que a educação implica um vínculo com a temporalidade do mundo humano; que ela não se desenvolve a partir de um vazio histórico, mas de uma experiência de intercâmbio entre gerações que ocupam lugares distintos no mundo (Bárcena, 2009, p. 113-138).

Esse intercâmbio intergeracional pode tomar várias formas: da impregnação cultural por meio da convivência cotidiana entre gerações à sistematicidade do ensino escolar. Mas ele sempre supõe a presença pessoal de um mediador autorizado, capaz de familiarizar os que são novos no mundo com as sutilezas, a opacidade e as ambiguidades inerentes ao caráter simbólico do universo humano. O reconhecimento do vínculo de pertencimento a um universo cultural anterior - que se impõe aos recém-chegados como um mundo comum que os transcende e no qual devem ser iniciados - não impede o florescimento de um sujeito autônomo; é antes sua precondição. Como ressalta Gauchet (2002, p. 33), “o sujeito destinado à posse de si mesmo - o sujeito autônomo almejado pelos discursos pedagógicos modernos deve ser instituído. Ele precisa passar por um outro para aceder a si mesmo”. Esse sujeito não se encontra, pois, como uma potencialidade psicológica que antecede o processo formativo; é antes a expressão de um ideal político a orientar os objetivos da formação educacional. Por isso, "postulá-lo na origem é, na verdade, uma forma de impedir seu surgimento” (idem, p. 41).

Ao rejeitar a autoridade escolar como traço constitutivo da experiência formativa, as pedagogias da autonomia não a eliminam do contexto social, mas apenas favorecem a emergência e a consolidação de simulacros de autoridade em novos espaços e personagens sociais, como os ídolos midiáticos ou os profetas da autoajuda. É uma renúncia de consequências políticas particularmente graves, uma

$6 \mathrm{Na}$ conclusão de sua obra, Houssaye chega a afirmar que "a pedagogia pode mesmo ser lida como essa imensa tentativa constantemente renovada de excluir a autoridade do ato educativo" (2007, p. 181). 
vez que incidem sobre a representação que uma instituição pública - de presença capilar nas sociedades modernas - tem acerca de si mesma e sobre a legitimidade de sua tarefa cotidiana e de seus compromissos sociais.

É verdade que, sob a égide do poder estatal e dos ditames do mercado, o significado público da formação educacional tem muitas vezes cedido passo à mera conformação social a partir de práticas impregnadas de coerção e violência. É igualmente verdadeiro que muitas vezes lança-se mão do termo autoridade para justificar o que não passa de uma tentativa dissimulada de dominação e produção de uma obediência cega e sem sentido. Como alerta Gauchet (idem, p. 45), ao comentar esses descaminhos, "conhecemos bem as patologias da autoridade"; é preciso rejeitar inequivocamente suas manifestações no domínio das instituições escolares, "mas temos muito o que aprender acerca das patologias de uma pretensa liberdade que, ao dissolver as mediações necessárias, na verdade, deixa os indivíduos à mercê de uma autoridade invisível num mundo que se lhes escapa e os manipula".

Assim, não obstante a validade das denúncias acerca de suas patologias ou das formas coercitivas que pretendem substituí-las, a mera e imediata rejeição de qualquer relação de autoridade - bem como as tentativas de sua restauração com base em modelos que se dissiparam em nossa experiência histórica - acaba por nos impedir de enfrentar a tarefa de pensar um lugar para a autoridade a partir da especificidade de nossa condição histórica. Em sua pressa para restaurar um passado ou em sua urgência de rejeitá-lo, a maior parte dos discursos educacionais contemporâneos parece ignorar o fato de que, em meio a uma crise:

[...] não tem muito sentido agirmos como [...] se apenas houvéssemos nos extraviado de um caminho certo e estivéssemos livres para, a qualquer momento, retomar o velho rumo. [...] Não se pode, onde quer que a crise haja ocorrido no mundo moderno, seguir em frente, tampouco simplesmente voltar para trás. Tal retrocesso nunca nos levará a parte alguma, exceto à mesma situação da qual a crise acabou de surgir. [...] Por outro lado, a mera e irrefletida perseverança, seja pressionando para a frente a crise, seja aderindo à rotina que ingenuamente acredita que ela não afetará sua esfera particular de vida, só pode conduzir à ruína, visto que se rende ao curso do tempo; para ser mais precisa, ela só pode aumentar o estranhamento do mundo pelo qual já somos ameaçados de todos os flancos. Ao considerar os princípios da educação, temos de levar em conta esse processo de estranhamento do mundo; pode-se mesmo admitir que presumivelmente nos defrontemos aqui com um processo automático, desde que não esqueçamos que está ao alcance do poder do pensamento e da ação humana interromper e deter tais processos. (Arendt, 2006, p. 191)

Nesse sentido, refletir sobre a crise da autoridade - em seu vínculo essencial com a temporalidade - à luz dos problemas do presente é uma forma de recusar, ao mesmo tempo, tanto a restauração como o banimento sumário do lugar de autoridade nas relações educativas. Adotar tal perspectiva implica considerar a especificidade histórica da experiência política romana, que marcou o surgimento do conceito de autoridade. Implica ainda reconhecer as profundas transformações que têm afe- 
tado as formas pelas quais pensamos e descrevemos as experiências com o tempo e a autoridade a partir da era moderna; mas não se resume ao reconhecimento da historicidade do conceito nem à variedade de experiências com ele identificadas, a despeito da inegável importância de ambos os aspectos. Vincular a noção de autoridade à temporalidade implica, sobretudo, considerar que a durabilidade e a renovação de um mundo comum dependem da natureza das relações intergeracionais que nele se estabelecem. É, pois, do intercâmbio entre gerações que já se encontram no mundo e as que nele acabam de aportar que emerge uma ligação temporal capaz de dar algum grau de durabilidade ao mundo comum, pois, se o mundo "deve conter um espaço público, não pode ser construído apenas para uma geração e planejado somente para os que estão vivos, mas tem de transcender a duração da vida de homens mortais" (Arendt, 2010, p. 67).

Esse caráter transcendente e durável do mundo público não se confunde com uma representação de tempo que o concebe como um desenvolvimento contínuo e homogêneo, a exemplo da concepção moderna de progresso histórico. Ao contrário, em Arendt, a preocupação com a durabilidade do mundo público admite rupturas e assume a fragilidade como marca do mundo humano. Por ser produto do engenho humano e de sua capacidade de fabricação e instituição, o mundo comum está sempre e "irrevogavelmente fadado à ruína pelo tempo, a menos que existam seres humanos determinados a intervir, a alterar, a criar aquilo que é novo" (Arendt, 2006, p.189). Durabilidade e ruptura não se excluem; antes se complementam. Só em um mundo dotado de durabilidade pública - um mundo que acolhe em seu seio os novos, que os transforma em herdeiros autorizados de seu passado e agentes responsáveis por seu futuro - é possível instituir o novo.

Sem permanência nem durabilidade, não há início nem fim; só o fluxo contínuo de um ciclo vital que se perpetua pela reprodução de indivíduos e pela continuidade das espécies. Assim, a autoridade - condição da possibilidade da transmissão intergeracional - vincula-se às formas pelas quais uma cultura dialoga com seus antepassados e com seus sucessores. É, pois, o caráter transcendente do mundo público - e a consequente assunção da responsabilidade pela durabilidade de uma herança comum de realizações simbólicas - que autoriza o lugar do educador na relação pedagógica. Um lugar sempre sujeito ao frágil equilíbrio entre o legado do passado e a abertura ao futuro, um lugar sempre instável em face da variedade de experiências históricas que fazem da autoridade um elo entre os educandos e um mundo de heranças e de promessas.

\section{AUTORIDADE E TEMPORALIDADE: DA SACRALIDADE DA FUNDAÇÃO AOS DESAFIOS DO PRESENTISMO}

A autoridade como fator decisivo em uma ordem política - e elemento norteador de sua prática educativa - não é um fenômeno universal. A palavra e o conceito de auctoritas são romanos e têm sua origem no verbo augere (aumentar, fazer crescer; desenvolver, intensificar) e no substantivo auctor (autor, aquele que cria, que dá origem ou funda; o que aprova, sanciona; o que defende, protege). 
No plano jurídico privado da Roma republicana, por exemplo, é a auctoritas que assegura - e, assim, aumenta e intensifica - a validade de um ato. Ao avalizá-lo, ela não institui seu valor jurídico (que já existia!), mas lhe atesta maior credibilidade. Já no âmbito político, é a auctoritas do Senado que avaliza a legitimidade de uma lei ou iniciativa, que atesta sua conformidade com a tradição, sua afinidade com os princípios da fundação de Roma.

A palavra autorizadora do Senado não se confunde com o poder (potestas) do povo ou dos magistrados, mas tem um valor performático: ao ser proferida, torna-se capaz de imprimir uma legitimidade que se pretende acima das disputas e dos interesses do presente. Sua eficácia simbólica advém do fato de que ela se enraíza nas lições transmitidas pelo passado, na grandeza do exemplo dos ancestrais e na transmissão desse legado vinculatório. Noutras palavras, sua eficácia derivava da traditio - a tradição romana em todas as suas complexas acepções. Assim, embora não tenha nem poder executivo, nem caráter mandatório, a auctoritas do Senado tem reconhecimento. Sua palavra legitima-se como uma fonte de sabedoria cristalizada no tempo, pois tem a função de ligar o presente à sacralidade ancestral da fundação:

No âmago da política romana, desde o início da República até virtualmente o fim da era imperial, encontra-se a convicção do caráter sagrado da fundação, no sentido de que, uma vez que tenha sido fundada, uma coisa permanece vinculatória [binding] para todas as gerações futuras. Tomar parte na política significava, antes de mais nada, preservar a fundação da cidade de Roma. (idem, p. 120)

Essa vinculação do ato político à fundação não significa que as instituições conservavam uma identidade imutável - de resto, impossível -, mas que as transformações eram acompanhadas de um movimento de apropriação do passado, de transformação do presente à luz da tradição, ou seja, da autoridade do passado como critério para as escolhas e ações do presente. Daí a crença de Catão de que a superioridade da Constituição Romana devia-se ao fato de ela não ser obra de um único homem, nem de uma única geração, mas o produto de uma pluralidade de homens ao longo de várias gerações. Nesse sentido, o caráter público de sua instituição derivava da pluralidade, tanto em sua dimensão espacial e presente como em sua dimensão temporal e histórica, por meio da apropriação que fazia do passado. Era o enraizamento da experiência política romana no tempo que lhe conferia estabilidade em meio às transformações e que possibilitava que a inovação viesse a ser concebida como continuidade, crescimento e aumento da fundação.

Era, pois, a autoridade do passado que criava uma comunidade política e cultural entre a fundação de Roma, seu presente e todos os esforços no sentido de sua continuidade ou imortalização. Ela conferia um lastro temporal à existência comum:

A substância da auctoritas romana é o tempo, é o acréscimo temporal que produz a autoridade. $\mathrm{O}$ tempo é autoridade. $\mathrm{E}$ o outro nome dessa autoridade é a instituição: a instituição política de um mundo comum não é só espacial (por meio da edificação de um espaço público), mas também temporal (por meio da instituição da durabilidade do domínio público). A autoridade supera, desse 
modo, a alternativa entre a eternidade da natureza e a efemeridade da convenção. (Revault D'Allonnes, 2006, p. 33)

Assim, a instituição de um domínio público e político enraizado no tempo enseja a possibilidade da durabilidade do mundo comum como uma resposta ao caráter mortal da existência humana. Os homens são mortais, mas Roma é imortal. ${ }^{7}$ É pela preservação desse mundo - das obras e instituições que o constituem como palco para a dimensão política da existência humana - e da memória de feitos e palavras notáveis daqueles que o construíram que o passado atualiza-se e imortaliza-se. Sem a instituição desse elo temporal, que vincula as sucessivas gerações entre si e com um mundo comum que as antecede, a existência humana resumir-se-ia à participação no sempiterno ciclo biológico vital, sem ser capaz de instituir o novo e dar-lhe bases de permanência como um legado material e simbólico.

$\mathrm{Na}$ verdade, a própria noção de geração implica essa possibilidade de transmissão e apropriação de um legado material e simbólico, pois, sem ele, só haveria a reposição natural e contínua de membros da mesma espécie, e não se poderia falar em continuidade ou ruptura entre gerações. A existência de um intercâmbio intergeracional depende, pois, da transmissibilidade da experiência. São as diferentes formas de se relacionar com o legado de experiências intergeracionais que marcam a atitude de uma cultura em face da autoridade. Em Roma, a tradição-o respeito que vinculava cada sucessiva geração à fundação - gerava a autoridade e "transforma[va] a verdade em sabedoria, e a sabedoria [portava] a consistência da verdade transmissível" (Arendt, 1998, p. 168).

Por essa razão, embora originariamente vinculada aos domínios jurídico e político, a ligação entre verdade, sabedoria e a autoridade do passado acabou por ter um papel central em diversos outros âmbitos da vida romana. No plano religioso, por exemplo, ela estava presente nos auspícios que aprovavam ou desaprovavam as escolhas dos homens, como no lendário episódio em que os deuses autorizam Rômulo a fundar a cidade no Palatino. Mas é no plano das relações educativas que a transmissibilidade da tradição cumpre mais claramente o papel de fazer da autoridade o elo a vincular o presente e o porvir ao passado e aos ancestrais. Daí a importância educativa que os romanos atribuíam aos mitos fundacionais e às narrativas acerca dos grandes homens do passado: os maiores, cuja grandeza deveria servir como modelo aos que acabavam de chegar ao mundo. Um princípio formativo que encontra sua síntese nas palavras de Políbio, para quem educar os mais jovens era simplesmente "fazer-vos ver que sois inteiramente dignos de vossos antepassados" (Arendt, 2006, p. 191).

Eram a reverência ao passado e a firme crença de que suas lições iluminavam o presente e estendiam seu valor às gerações futuras que autorizavam o educador a constituir-se em mediador legítimo entre a herança simbólica ancestral e aqueles

7 Revault D'Allonnes (2006) destaca que, a fim de designar uma duração infinita que escapa ao mundo humano - próxima à noção cristã de eternidade -, os romanos usavam o termo neutro aevum, enquanto os termos perpetus e aeternus referem-se à durabilidade do que é vivido pelo homem. 
que dela precisavam aproximar-se a fim de ascender plenamente à sua condição de herdeiros e continuadores de uma cultura (ou seja, de ascender à sua bumanitas). Essa forma de conceber a relação entre passado, tradição e autoridade sobreviveu ao colapso de Roma. O cristianismo deu-lhe um novo conteúdo (o Novo Testamento como narrativa da fundação, a hagiografia como lição exemplar...), mas sem pôr em questão os pressupostos sobre os quais se assentara a noção de autoridade fundada na tradição, no caráter exemplar de vidas e eventos do passado. ${ }^{8} \mathrm{E}$, mesmo na era moderna, não obstante a profunda diferença de sua atitude em relação ao passado, é possível encontrar formas residuais desse tipo de ligação temporal como fundamento da autoridade.

As narrativas fundacionais dos Estados nacionais são um claro exemplo da persistência desse caráter autorizador dos princípios associados ao ato instituinte de uma comunidade política. Tome-se como exemplo o discurso de posse de Barack Obama na presidência dos Estados Unidos da América do Norte, em 2009. Nele há inúmeras alusões à fundação e ao passado como elementos legitimadores, como referências comuns capazes de aumentar e intensificar o valor simbólico de suas escolhas, inserindo-as na continuidade desse espírito inaugural. Assim, Obama (2009) refere-se reiteradamente ao caráter orientador dos documentos fundacionais e alude à necessidade de respeitarem-se os sacrifícios dos ancestrais e a atitude corajosa dos pais fundadores, que, mesmo em meio a lutas ameaçadoras, jamais abriram mão do respeito à lei e aos direitos humanos. É, pois, a evocação de um modelo fixado em narrativas de um passado referencial - os pais fundadores na América do Norte, ou os libertadores na América Latina, ou a revolução, ou a proclamação da república - que autoriza os atos do presente. É a alegada vinculação a um episódio instituinte - ou aos que são considerados responsáveis por ele - que legitima compromissos, que dá crédito a princípios e valores que se querem transcendentes às contingências do presente e às idiossincrasias pessoais; é o passado reconhecido como referência que produz autoridade.

Mas o reconhecimento da presença residual da autoridade fundada na tradição não deve elidir o fato de que, pelo menos desde a consolidação da modernidade, a ideia de sacralidade do passado e de seu caráter vinculante em relação às novas gerações passa a ser objeto de uma crítica sistemática e radical. Os tempos modernos, e em especial o Iluminismo, não têm de si uma imagem de continuidade ou simples renovação em relação ao passado. Ao contrário, sua autoimagem é antes ligada à vontade de instituição do novo, de uma ruptura com a autoridade do passado. À autoridade do passado opõe-se a autoridade da razão, que se crê emancipada - ou ao menos em via de emancipação - de toda sorte de "grilhões de uma perpétua menoridade a impedir os homens de pensar por si mesmos" (Kant, 1983, p. 102).

8 É evidente que o Cristianismo introduz também mudanças significativas na noção de autoridade, como a transposição de sua fonte última para um plano que transcende o mundo humano ou ideia de uma sanção futura como elemento coercitivo. Contudo, interessa aqui ressaltar que, a despeito dessas profundas transformações, ele mantém a mesma atitude de reverência ao passado e a mesma crença em seu papel formativo. 
No plano político, há uma crescente rejeição de qualquer justificativa do poder assentada na transcendência de seu fundamento ou na sacralidade do passado. A noção de contrato social, fruto do assentimento de indivíduos iguais em direitos e semelhantes pela natureza, engendra a progressiva recusa de toda sorte de hierarquias previamente fundadas em uma suposta ordem natural - como as distinções por nascimento - ou na transcendência de uma tradição político-teológica. Mais que um princípio a ordenar o funcionamento das instituições políticas, a igualdade de condiçôes transforma-se em um ideal social, em uma ideia geradora que, segundo Tocqueville $(1985$, p. 57$)$, "acaba por atrair para si [...] todos os sentimentos e todas as ideias, como um grande rio em direção ao qual cada riacho parece correr". Assim, a democracia não se limita a uma forma de governo, mas passa a ter um valor simbólico extensivo a todos os domínios da vida social e é evocada como valor capaz de legitimar a busca da efetivação da igualdade universal de direitos e oportunidades. ${ }^{9} \mathrm{O}$ princípio da igualdade universal - é evidente - não abole as relações de dominação nem as desigualdades sociais, mas nelas introduz um elemento de arbitrariedade, uma vez que os lugares sociais não são mais fixados pelo nascimento nem por uma ordem estável e tida como transcendente. A potencial mobilidade social implicada na noção de igualdade de condições significa que, ao menos em princípio, o indivíduo pode passar de uma posição a outra na hierarquia social, que sua aspiração a ocupar um novo lugar é sempre legítima, a despeito dos impedimentos concretos para sua realização. Desse modo, a aceitação da igualdade como princípio axiológico e direito universal não aparece como incompatível com as desigualdades de fato, cuja origem e legitimidade passam a ser atribuídas a outros fatores, como o mérito individual.

Ora, em que pese seu caráter mais programático e imaginário do que real, a expansão do ideal igualitário moderno implicará um conflito direto com a pressuposição de uma assimetria legítima como precondição de todas as formas de intercâmbio entre gerações. E isso não só no sentido óbvio de que ele engendra uma negação do caráter hierárquico que presidia tais relações, mas também em decorrência do fato de que seu desenvolvimento foi solidário com uma profunda transformação na natureza do vínculo temporal que regia as relações intergeracionais. Para Tocqueville (idem, p. 10), o caráter igualitário e individualista da democracia moderna implica também uma profunda transformação nos "laços que unem as gerações entre si, levando os homens a perder o elo com as ideias de seus antepassados ou a não mais se preocuparem com seu curso e destino". Ao equipararem-se em direitos a todos os seus semelhantes vivos, os homens equiparam-se também àqueles que os precederam, a seus ancestrais, que não mais

9 Há, nesse sentido, uma flagrante distinção entre os ideais moderno e antigo de igualdade. $\mathrm{Na}$ Grécia democrática, a igualdade era um atributo exclusivo das relações políticas e convivia com a ideia do caráter natural de todas as formas de hierarquia e dominação: entre homens e mulheres, entre senhores e escravos etc. A postulação moderna de uma igualdade universal convive com as desigualdades de fato, mas recusa-lhes uma legitimidade natural, abrindo espaço para toda sorte de questionamentos a desigualdades que não se devam a um suposto mérito individual. 
determinam seu lugar no mundo. Seu valor deixa de ser, por si, exemplar, para ser compreendido à luz de um processo de desenvolvimento contínuo; substitui-se a reverência ao passado pelo culto ao futuro como fonte de autorização.

Tece-se assim, no seio da era moderna, uma nova "forma de se traduzir e de se ordenar a experiência do tempo - uma [nova] maneira de se articular o presente, o passado e o futuro - e de lhes atribuir um sentido; ou seja, um novo regime de temporalidade" (Hartog, 2012, p. 147). Em lugar de histórias exemplares de um tempo pretérito, entra em cena a História - no singular -, concebida como um processo homogêneo, linear e contínuo. Diferentemente das histórias dos eventos de um mundo específico e de seus agentes - como o romano ou o cristão -, a História não tem fundação; é um processo que se estende ao infinito e cujo sentido (na dupla acepção de significado e direção) deve ser compreendido e captado em sua totalidade. Não é mais o passado que ilumina o presente e reafirma-se no futuro; é o sentido que se atribui ao desenvolvimento histórico - a teleologia de um progresso - que empresta à infinidade de eventos aparentemente aleatórios um sentido articulado:

$\mathrm{Na}$ historia magistra, o exemplar ligava o passado ao futuro por meio do modelo a ser imitado. [...] Com o regime moderno, o exemplar em si desaparece, para dar lugar ao que não mais se repete. $\mathrm{O}$ passado é por princípio ou, o que dá no mesmo, por posição, ultrapassado. [...] Se ainda há uma lição da história, ela vem do futuro, e não mais do passado. Ela está num futuro que emergirá como ruptura com o passado, ou ao menos como diferente dele. (idem, p. 145-146)

A era moderna recusa o caráter exemplar do passado e sua autoridade sobre o presente como fonte legitimadora da ação educativa. Mas essa recusa não implica o abandono da responsabilidade pelo vínculo temporal como eixo articulador do intercâmbio intergeracional; ela o transporta para o futuro. É o sentido do devir histórico, o fim (télos) para o qual concorre o progresso, que passa a autorizar o ato educativo e dotá-lo de um significado. A educação passa a ser concebida como preparação para um destino histórico, seja ele vislumbrado como a superação de um modo de produção ou como o advento de uma era marcada pela positividade da ciência e pelo desenvolvimento tecnológico, como processo de emancipação política ou de expansão ilimitada da produção e do consumo. Daí a profusão dos slogans e máximas segundo as quais a educação é a condição para a plena realização do futuro; já não importa formar jovens dignos de seus antepassados - trata-se de prepará-los para fazer frente às novidades do futuro.

A essa tarefa, a escola moderna parece inicialmente responder de uma forma singular e paradoxal: sem recusar como finalidade a preparação do indivíduo autônomo e comprometido com o devir histórico, ela conserva o legado da tradição como meio para sua realização. É pelo acesso à cultura letrada, a uma herança simbólica enraizada em saberes, linguagens e práticas das quais se crê legítima difusora, que a escola vislumbra sua forma peculiar de cumprir uma função pública e de se colocar à altura do vínculo histórico que lhe foi confiado pela era do progresso. $\mathrm{Na}$ escola moderna, era a força do passado que autorizava a construção do futuro.

É só com a crítica da crença no progresso, com a ascensão do que Hartog (idem, p. 156) classifica como presentismo - "o progressivo esvanecimento do 
horizonte futuro por um presente cada vez mais adensado, hipertrofiado" -, que o próprio sentido formativo da transmissão de um legado de experiências simbólicas surge para os educadores como um desafio incontornável. A emergência do totalitarismo, a ameaça atômica e ambiental, o esfacelamento dos Estados nacionais não representaram só a ruptura da tradição; engendraram também a desconfiança no futuro como um tempo de promessa. Sob a pressão "de exigências cada vez maiores de uma sociedade de consumo na qual as inovações tecnológicas e a busca de lucro cada vez mais rápido, desenvolve-se um processo vertiginoso de aceleração no ritmo de obsolescência das coisas e dos homens" (idem, ibidem) e cria-se um regime de temporalidade em que já não é mais o passado ou o futuro que emite a luz que ilumina o presente e cria um vínculo temporal entre as gerações - é o presente que ilumina a si mesmo. Em maio de 1968, os muros de Paris anunciavam o sentimento de urgência do presentismo como forma de se relacionar com o tempo: "Tout, tout de suite" (Tudo já!).

O caráter imediatista do presente desafia a educação em seus fundamentos e métodos: em sua tarefa básica de estabelecer um diálogo intergeracional capaz de imprimir durabilidade a um mundo comum e em sua crença de que o objeto por meio do qual esse diálogo realiza-se é a iniciação em um legado específico de experiências simbólicas. Sob a pressão desse presente imediato, os discursos educacionais têm procurado imprimir à prática educativa um novo sentido, supostamente mais afinado com as exigências de produtividade, flexibilidade e mobilidade que orientam as preocupações gerenciais e mercadológicas típicas do presentismo contemporâneo. Mas o preço da eficácia de sua adaptação e conformação à temporalidade dominante pode ser a perda de seu sentido histórico.

\section{REFERÊNCIAS}

Arendt, H. Homens em tempos sombrios. São Paulo: Companhia das Letras, 1998. . Between the past and the future. New York: Penguin, 2006. A condição humana. Rio de Janeiro: Forense, 2010.

BÁRCENA, F. Una pedagogía del mundo: aproximación a la filosofía de la educación de Hannah Arendt. Anthropos: Huellas del Conocimiento, La Rioja: Proyecto A Ediciones, n. 224, p. 113-138, 2009.

Brasil. Câmara dos Deputados. Projeto de lei n. 267, de 8 de fevereiro de 2011. Acrescenta o artigo 53-A à lei n. 8.069, de 13 de julho de 1990, que "dispõe sobre o Estatuto da Criança e do Adolescente e dá outras providências", a fim de estabelecer deveres e responsabilidades à criança e ao adolescente estudante. Brasília, 2011. Disponível em: <http://www.camara.gov.br/proposicoesWeb/fichadetramitacao?idPr oposicao=491406 $>$. Acesso em: 11 jul. 2012.

Gadamer, H.-G. Verdade e método. Petrópolis: Vozes, 1999.

Gauchet, M. Pour une philosophie politique de l'éducation. Paris: Bayard, 2002.

Hartog, F. Régimes d'historicité: présentisme et expérience du temps. Paris: Seuil, 2012. 
Houssaye, J. Autorité ou éducation. Paris: ESF, 2007.

Kant, I. Textos seletos. Petrópolis: Vozes, 1983.

Lins, I.; Martins, V. Aos nossos filhos. Intérprete: Ivan Lins. In: Lins, I. Millennium. [S.1.]: Universal, 1999. (Mercury)

Овама, B. Barack Obama's inaugural address. The New York Times, New York, 20 jan. 2009. Disponível em: <http://www.nytimes.com/2009/01/20/us/politics/20text-obama. html?pagewanted=all $>$. Acesso em: 11 jul. 2012.

Renaut, A. La fin de l'autorité. Paris: Flammarion, 2004.

Revault D'Allones, M. Le pouvoir des commencements: essai sur l'autorité. Paris: Seuil, 2006.

Ricoeur, P. Le paradoxe de l'autorité. In: Le juste 2. Paris: Esprit, 2001.

Toceueville, A. De la démocratie en Amérique. Paris: Michel Levy, 1985. Tome 1.

\section{SOBRE O AUTOR}

José Sérgio Fonseca de Carvalho é doutor em educação pela Universidade de São Paulo (USP). Professor da mesma instituição.

E-mail: jsfcusp@usp.br 